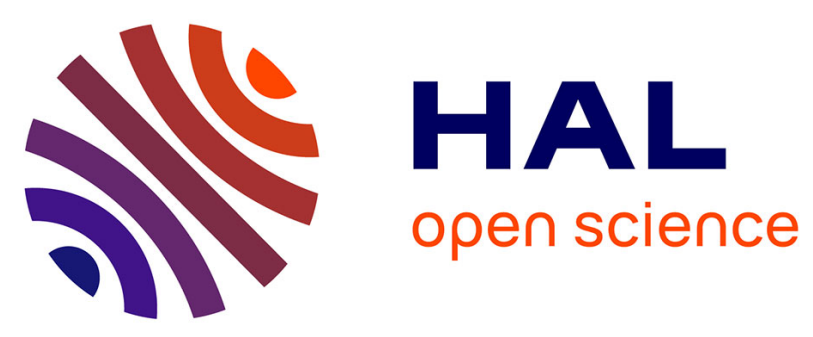

\title{
Poor assessment of bone mineral density after a forearm fracture in women aged 50 years or older: Data from a French health insurance database
}

\author{
Elsa Cattelain-Lopez, Delphine Chu Miow Lin, André Happe, Philippe
}

Goupille, Emmanuel Oger, Denis Mulleman

\section{To cite this version:}

Elsa Cattelain-Lopez, Delphine Chu Miow Lin, André Happe, Philippe Goupille, Emmanuel Oger, et al.. Poor assessment of bone mineral density after a forearm fracture in women aged 50 years or older: Data from a French health insurance database. Joint Bone Spine, 2021, 88 (2), pp.105121. 10.1016/j.jbspin.2020.105121 . hal-03129798

\section{HAL Id: hal-03129798 \\ https://hal.science/hal-03129798}

Submitted on 25 Feb 2021

HAL is a multi-disciplinary open access archive for the deposit and dissemination of scientific research documents, whether they are published or not. The documents may come from teaching and research institutions in France or abroad, or from public or private research centers.
L'archive ouverte pluridisciplinaire HAL, est destinée au dépôt et à la diffusion de documents scientifiques de niveau recherche, publiés ou non, émanant des établissements d'enseignement et de recherche français ou étrangers, des laboratoires publics ou privés. 
Authors: Elsa Cattelain-Lopez ${ }^{1,2 *}$, Delphine Chu Miow Lin ${ }^{1,2^{*}}$, André Happe ${ }^{3}$, Philippe Goupille $^{1,2}$, Emmanuel Oger ${ }^{4,5}$ and Denis Mulleman ${ }^{1,2}$

* Both authors contributed equally

\author{
Affiliations \\ 1. Université de Tours, 37000, Tours, France \\ 2. Service de rhumatologie, CHRU de Tours, 37044 Tours cedex 9, France \\ 3. UPRES-EA 7449 REPERES, CHRU de Brest, 29200, Brest, France \\ 4. Centre Régional de Pharmacovigilance, Pharmaco-épidémiologie et information sur le \\ médicament, CHRU de Rennes, 35000, Rennes, France \\ 5. UPRES-EA 7449 REPERES, Université de Rennes 1, 35000, Rennes, France
}

\title{
Corresponding author:
}

Denis Mulleman

Service de Rhumatologie - CHRU de Tours - 37044 Tours Cedex 9

Phone: +33 247475917; Fax: +33 247479156; denis.mulleman@univ-tours.fr

Ethics approval and consent to participate: Not applicable

Consent for publication: Not applicable

Availability of data and materials: The datasets used and/or analyzed during the current study are available from the corresponding author on reasonable request. 


\section{Letter to the Editor,}

Poor assessment of bone mineral density after a forearm fracture in women aged 50 years or older: data from a French health insurance database

Forearm fractures should be considered as an early sign of osteoporosis.[1] In 2010, 47,131 forearm fractures occurred in France, a country that comprises $22.5 \%$ women $\geq 50$ years old and 2.8 million osteoporotic patients.[2] In a recent meta-analysis, the risk of a subsequent hip fracture was reported to be increased in women who presented a forearm fracture.[3] Thus, bone mineral density (BMD) testing is recommended after a forearm fracture to assist clinicians in decision making.[4] We previously reported that in our district, only $10 \%$ of women $\geq 50$ years old had BMD testing after a forearm fracture.[5] However, the size of the population sample in that study was relatively small and it was restricted to the private sector.

We used the French national health insurance information system (Système National d'Information Inter Régimes de l'Assurance Maladie [SNIIRAM]),[6] which can be linked to the French medical program for information systems (Programme de Médicalisation des Systèmes d'Information [PMSI]), a medico-economic tool used for describing public or private hospital activity. The study included 4,120 women. Among the 4,120 women $\geq 50$ years old who had a forearm fracture between 2011 and 2012 in the Centre-Val de Loire area, 546 (13.3\%) had a BMD assessment in the year after the forearm fracture (Table 1). The median delay between the fracture and BMD testing was 117.5 days (range 4-365). Among the 3574 women without BMD testing, 231 (6.5\%) initiated or switched an anti-osteoporotic drug in the year after the fracture versus 168/546 women (30.8\%) who had BMD testing (OR=6.4, 95\% CI 5.2-7.9, $\mathrm{p}<0.001)$. Women with BMD testing were younger than those without BMD testing (mean age: 67.4 [SD 9.4] versus 74.6 [SD 12.1] y; $\mathrm{p}<0.001 ; \mathrm{OR}=0.94,95 \%$ CI 0.93-0.95) 
(Table 1). BMD testing was not associated with corticosteroids exposure on univariable analysis [35/297 (11.8\%) versus 511/3823 (13.4\%), OR=0.9, 95\% CI 0.6-1.2, $\mathrm{p}=0.439]$, but was associated with aromatase inhibitors [21/79 (26.6\%) versus 525/4041 (13.0\%), OR=3.2, 95\% CI 2.0-5.3, p<0.001]. BMD testing was performed most frequently in the Loir-et-Cher district (109 BMD tests, 19.2\%) and the least in Eure-et-Loir (55 BMD tests, 9.8\%). By contrast, accessibility to BMD testing was lower in Loir-et-Cher (3.97 densitometers per 100,000 women $\geq 50$ years old) and higher in Eure-et-Loir and Loiret districts (14.23 and 13.12 densitometers per 100000 women $\geq 50$ years old). Having a comorbidity reduced the odds of BMD testing [184/1833 (10\%) versus 362/2287 (15.8\%), $\mathrm{p}<0.001 ; \mathrm{OR}=0.6(95 \%$ CI 0.5-0.7)]. The comorbidities in patients with or without BMD are presented in the supplemental table.

This finding confirms previous works and stresses the need to implement these guidelines in clinical practice.[5, 7] BMD testing was less frequent for women with than without comorbidities. This finding may be explained by a lesser attention given to the prevention of osteoporosis as compared with other diseases. In our study, aromatase inhibitors was associated with increased frequency of BMD assessment which is in good agreement with the recommendations for patients who receive such drugs. We found no association between accessibility to BMD testing and proportion of BMD tests performed. Since there is no apparent bias in identification of BMD assessment, the availability of BMD machines does not explain these inter-district differences.

To prevent secondary fracture, several successful initiatives such as Fractures Liaisons Service (FLS) were promoted.[8, 9] FLS have significantly decreased the fracture rate and increased anti-osteoporotic drug prescription in one study.[10] FLS, along with local communication campaigns, may help prevent osteoporosis after a forearm fracture in women. In 2017 we launched a FLS after forearm fracture in our hospital. Based on the present work, we will investigate the further trend of BMD assessment in our setting. 
Competing interests: The authors declare that they have no competing interest.

Funding: This work was supported by grants from the Osteoporosis Research and Information Group (GRIO - Groupe de Recherche et d'information sur les ostéoporoses) in 2013 and the French League Against Rheumatism (AFLAR - Association Française de Lutte AntiRhumatismale) in 2014.

Authors' contributions: ECL analyzed the results and drafted the manuscript; DCML and DM initiated and coordinated the work, participated in the analyses and drafted the manuscript; PG contributed to the development of the work; AH, EO and ECL performed the statistical analyses; EO, DCML participated in the analyses. All authors read and improved the entirety manuscript and contributed actively to the study.

Acknowledgements: We thank Caroline Rault (CHU de Rennes, UPRES-EA 7449 REPERES) ; Florence Erny, François Jacquot and Philippe Tauveron (Centre de l'Ostéoporose, Tours); Ken Haguenoer and Emmanuel Rusch (Service d'Information Médicale, d'Epidémiologie et d'Economie de la Santé, Laboratoire de santé publique, CHRU de Tours). This work would not have been possible without the support of Mehdi Gabbas, CNAM-TS (Caisse Nationale de l'Assurance Maladie des Travailleurs Salariés) (Paris), Valérie Edel, INDS (Institut Nationale des données de Santé). This article is the result of the "Prevention of osteoporosis after distal forearm fracture (Prévention de l'Ostéoporose après fracture du Poignet [POP])" study group. 


\section{References}

[1] Klotzbuecher CM, Ross PD, Landsman PB, Abbott TA, 3rd, Berger M. Patients with prior fractures have an increased risk of future fractures: a summary of the literature and statistical synthesis. J Bone Miner Res 2000;15(4):721-39.

[2] Hernlund E, Svedbom A, Ivergård M, Compston J, Cooper C, Stenmark J, et al. Osteoporosis in the European Union: medical management, epidemiology and economic burden. A report prepared in collaboration with the International Osteoporosis Foundation (IOF) and the European Federation of Pharmaceutical Industry Associations (EFPIA). Arch Osteoporos 2013;8(1-2):136.

[3] Johnson NA, Stirling ER, Divall P, Thompson JR, Ullah AS, Dias JJ. Risk of hip fracture following a wrist fracture-A meta-analysis. Injury 2017;48(2):399-405.

[4] Briot K, Cortet B, Thomas T, Audran M, Blain H, Breuil V, et al. 2012 update of French guidelines for the pharmacological treatment of postmenopausal osteoporosis. Joint Bone Spine 2012;79(3):304-13.

[5] Erny F, Auvinet A, Chu Miow Lin D, Pioger A, Haguenoer K, Tauveron P, et al. Management of osteoporosis in women after forearm fracture: data from a French health insurance database. Joint Bone Spine 2015;82(1):52-5.

[6] Martin-Latry K, Begaud B. Pharmacoepidemiological research using French reimbursement databases: yes we can! Pharmacoepidemiol Drug Saf 2010;19(3):25665.

[7] Viprey M, Caillet P, Canat G, Jaglal S, Haesebaert J, Chapurlat R, et al. Low Osteoporosis Treatment Initiation Rate in Women after Distal Forearm or Proximal Humerus Fracture: A Healthcare Database Nested Cohort Study. PloS one 2015;10(12):e0143842. 
[8] Eisman JA, Bogoch ER, Dell R, Harrington JT, McKinney RE, Jr., McLellan A, et al. Making the first fracture the last fracture: ASBMR task force report on secondary fracture prevention. J Bone Miner Res 2012;27(10):2039-46.

[9] Ganda K, Puech M, Chen JS, Speerin R, Bleasel J, Center JR, et al. Models of care for the secondary prevention of osteoporotic fractures: a systematic review and meta-analysis. Osteoporos Int 2013;24(2):393-406.

[10] Lih A, Nandapalan H, Kim M, Yap C, Lee P, Ganda K, et al. Targeted intervention reduces refracture rates in patients with incident non-vertebral osteoporotic fractures: a 4-year prospective controlled study. Osteoporos Int 2011;22(3):849-58. 
Table 1: Characteristics of women $\geq 50$ years old with a forearm fracture in 2011 and 2012 in Centre-Val de Loire area in France by bone mineral density (BMD) testing in the year after the fracture

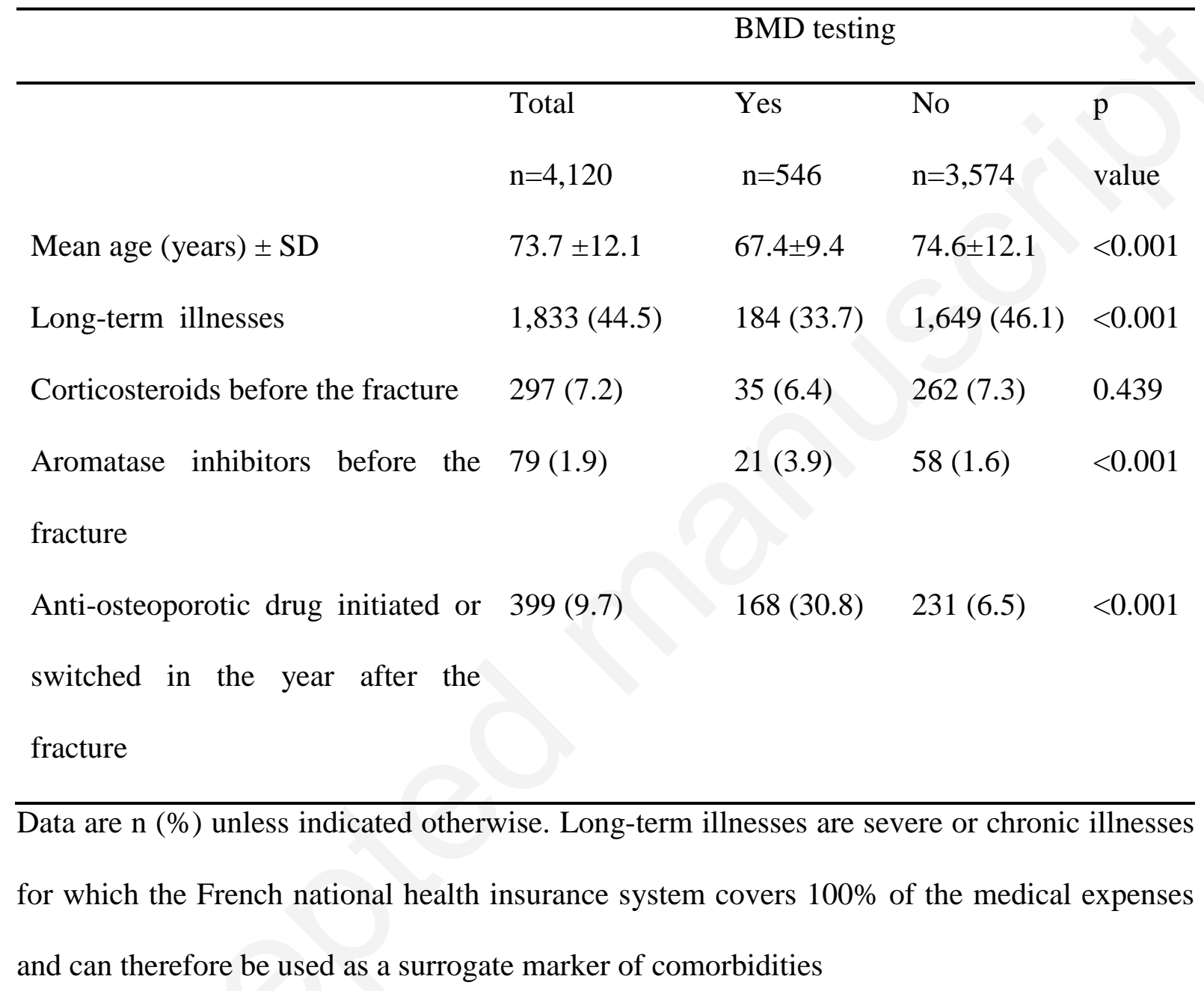


